

\title{
Visual Organization of Industrial Functional Compositions
}

\author{
Bujar Bajçinovci ${ }^{1}$,Vlora Aliu ${ }^{I^{*}}$ \\ ${ }^{1}$ University of Prishtina, "UP", Faculty of Civil Engineering and Architecture, Kosovo. \\ "Email:vloraa.aliu@gmail.com,.bujar.bajcinovci@uni-pr.edu
}

\begin{abstract}
The industry and transport system in the 20th Century have undergone cardinal transformations as a result of the development of science, technology, the growth of the economic base of society and the growth of the human living standards. Historically, Kosovo's industry has gone through various stages of its development and fully dependent on the economic system. In general, Kosovo's industrial development was based on the exploitation of raw materials and their processing to a certain degree, but not to a satisfactory degree of processing and finalization. Industrial complexes in recent decades 'moved' their traditional location of the suburban settlement and started a new phenomenon of industry selection locations even close to the city. Moreover, we have recently faced a lack of green spaces, and as a result we have come to the situation of redefining many urban architectural concepts, demanding free surfaces for non-degrading environmental industries in the urban zones. The industry today as a secondary economic activity is represented by $30 \%$ of production. Hence, designing industrial buildings poses urban and compositional challenges, especially when the production process implies the use of various technological equipment that can pollute the environment. Diversity of industrial building design must always be in line with the requirements of technological processes, economic development, environmental protection and sustainable social development. The study presented in this paper investigated the visual organization of industrial functional compositions, focussing on urban design issues, principles according to the Gestalt laws of grouping, and sustainable urban design. The research method consists of empirical observation through the wide Prishtina industrial zone, with an accent to the urban shapes, perception, and compositional harmony as a contemporary reflection to the past decisions of Prishtina municipality. Furthermore, the conceptual findings from the results of this research, will show the need and necessity of adopting the contemporary design strategies.
\end{abstract}

Keywords: Architecture, Urban design, Perception, Shape, Industry

\section{INTRODUCTION}

The industry and transport system in the 20th Century have undergone cardinal transformations as a result of the development of science, technology, the growth of the economic base of society and the growth of the human living standards. Historically, Kosovo's industry has gone through various stages of its development and fully dependent on the economic system. In general, Kosovo's industrial development was based on the exploitation of raw materials and their processing to a certain degree, but not to a satisfactory degree of processing and finalization. There is real cause for concern about the well-being of nature, and environment. Negative phenomena are reflected on our health, 
natural resources, economic, recreational and aesthetic occurrences. In general, it is hard to implement maxims of sustainability because of the difficulties that often accompany them: conflict of interests, market activities, private interests of users [1]. Industrial complexes in recent decades 'moved' their traditional location of the suburban settlement and started a new phenomenon of industry selection locations even close to the city. The industry today as a secondary economic activity is represented by $30 \%$ of production. Hence, designing industrial buildings poses urban and compositional challenges, especially when the production process implies the use of various technological equipment that can pollute the environment. Diversity of industrial building design must always be in line with the requirements of technological processes, economic development, environmental protection and visual harmony in structural compositions. In this context, humans have always been compelling to organize a group of space figures seemingly grouped without any order, in a layout with recognizable order in their perception, tending to link them with imaginary lines or making the effort to group in recognizable shapes, and thus making the whole visual organization easier to remember.

\section{MATERIALS AND METHODS}

It is evident that in visual perception we operate by crucial fundamental principles that make us to group visual system components in some meaningful recognizable forms. These logical criterions are of great importance in the architectural compositions, moreover, this visual grouping is indicative in the wide perceptual range, from the organization of simplest brick wall to the urban composition of metropolitan areas.

"It took me a long time to understand the relationship between ideas and between objective facts. But after I clearly understood this relationship, I didn't fool around with other wild ideas. That is one of the main reasons why I just make my scheme as simple as possible."

Ludwig Mies van der Rohe

Basically, there are five common principles according to the Gestalt laws of grouping that we tend to make the visual organisation of compositional functional elements:
a) The principle of Similarity
b) The principle of Proximity
c) The principle of Continuity
d) The principle of Closure
e) The principle of Connectedness 
According to the Vitruvius, Architecture depends on Order, Arrangement, Eurythmy, Symmetry, Propriety, and Economy [2].

1. "Order gives due measure to the members of a work considered separately, and symmetrical agreement to the proportions of the whole. It is an adjustment according to quantity. By this I mean the selection of modules from the members of the work itself and, starting from these individual parts of members, constructing the whole work to correspond" [2].

2. "Arrangement includes the putting of things in their proper places and the elegance of effect which is due to adjustments appropriate to the character of the work. Its forms of expression are these: groundplan, elevation, perspective "[2].

3. "Eurythmy is beauty and fitness in the adjustment of the members. This is found when the members of a work are of a height suited to their breadth, of a breadth suited to their length, and, in a word, when they all correspond symmetrically" [2].

4. "Symmetry is a proper agreement between the members of the work itself, and relation between the different parts and the whole general scheme, in accordance with a certain part selected as standard. Thus, in the human body there is a kind of symmetrical harmony between forearm, foot, palm, finger, and other small parts; and so, it is with perfect buildings" [2].

5. "Propriety is that perfection of style which comes when a work is authoritatively constructed on approved principles. It arises from prescription, from usage, or from nature" [2].

Nevertheless, the principle of similarity states that things which share visual characteristics such as [3]:
a) Shape;
b) Size;
c) Colour;
d) Texture;
e) Orientation.

Generally, will be seen as belonging together [3]. Hence, the elements of the same shape we tend to group in different compositions. 


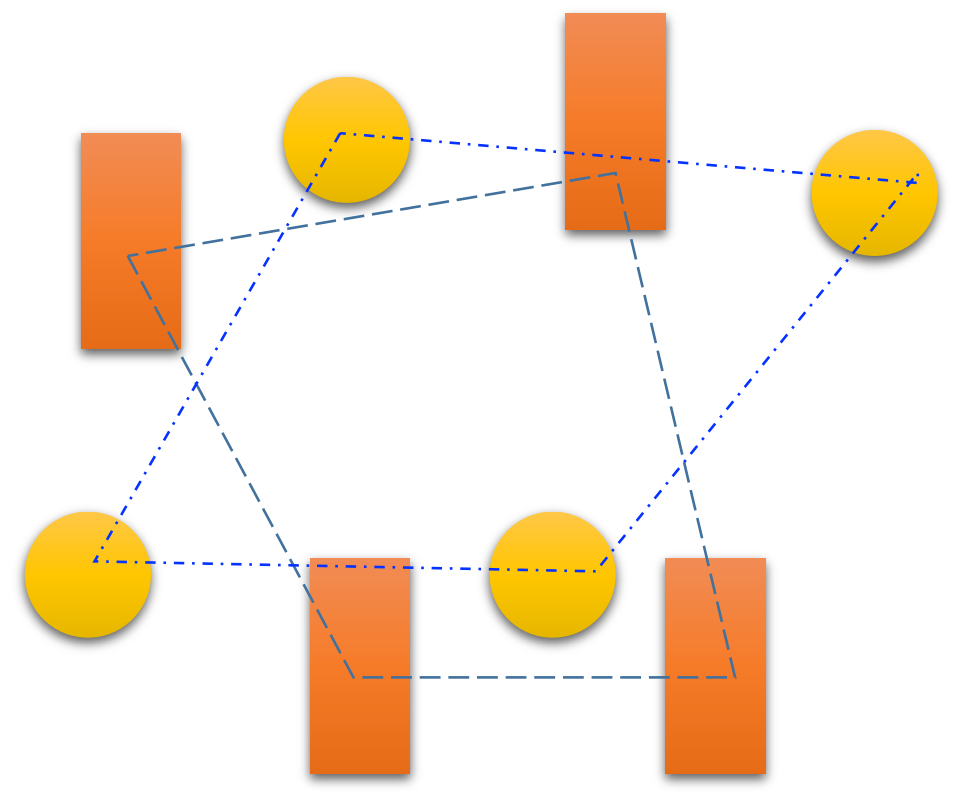

Figure 1. Rectangles form one group and circle another group in visual composition.

If elements are the same shape and different sizes, according to the Gestalt laws of grouping, they will be groping according to the size in separate groups unless the colour is present.

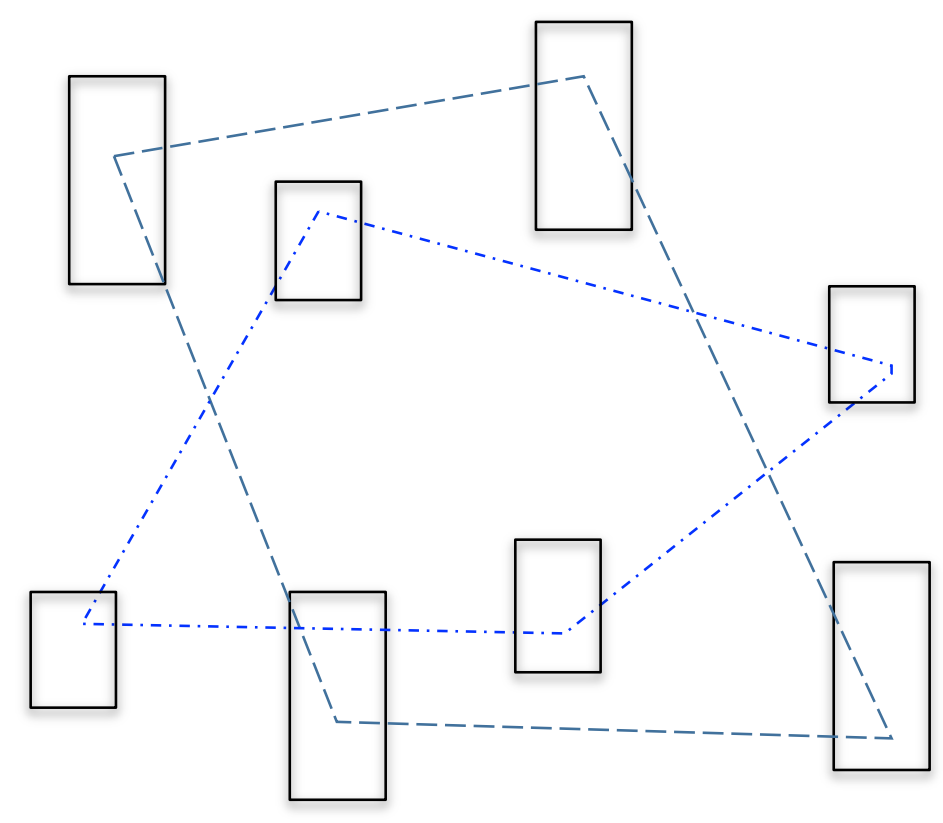

Figure 2. Big rectangles form one group and little ones another group, in visual composition.

Colour is a very powerful phenomenon that can further enhance the above-mentioned gestalt principles or can completely alter the effect. Colour enhances the much more the energy of the shape and creates greater contrast in between the architectural composition. 


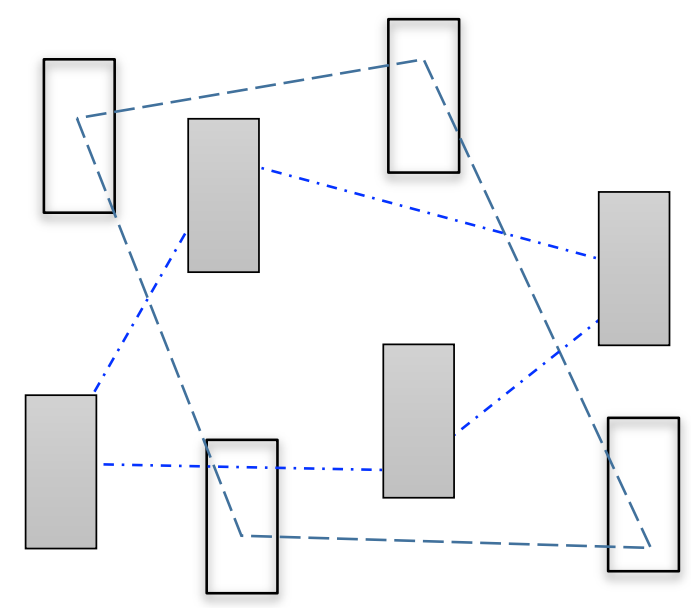

Figure 3. Coloured rectangles form one group and other rectangles another group, in visual composition.

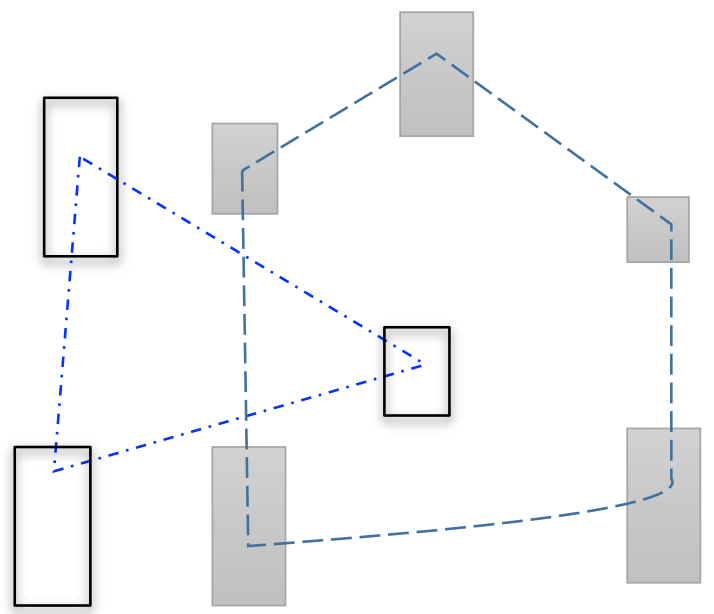

Figure 4. The colour has linked large and small rectangles into the same composition and thus cancelled the effect of similarity by the size.

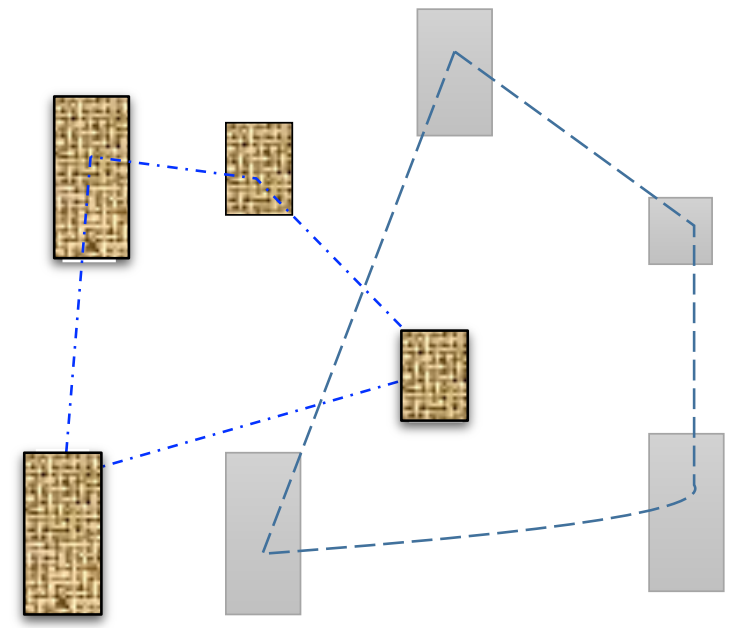

Figure 5. The texture has linked large and small rectangles into the same composition and also cancelled the effect of similarity by the size. 


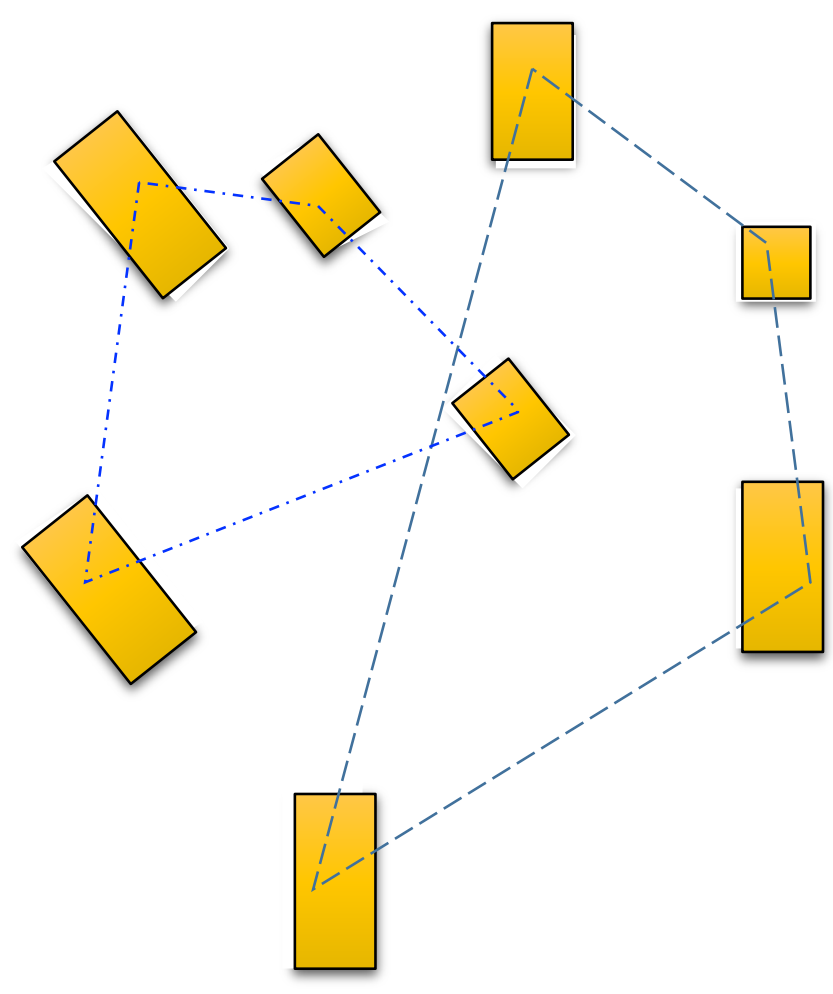

Figure 6 . The orientation has linked large and small rectangles into the same composition and thus cancelled the effect of similarity by the size.

According to the principle of Proximity, the proximity of the elements is a determining factor in the visual organization. Elements that are close enough to each another will be grouped in same visual composition. Hence, powerful and more intense elements will be ready to form a spatial composition to a somewhat larger distance. Nevertheless, each volume has a separate spatial energy that is dependent on their mass.
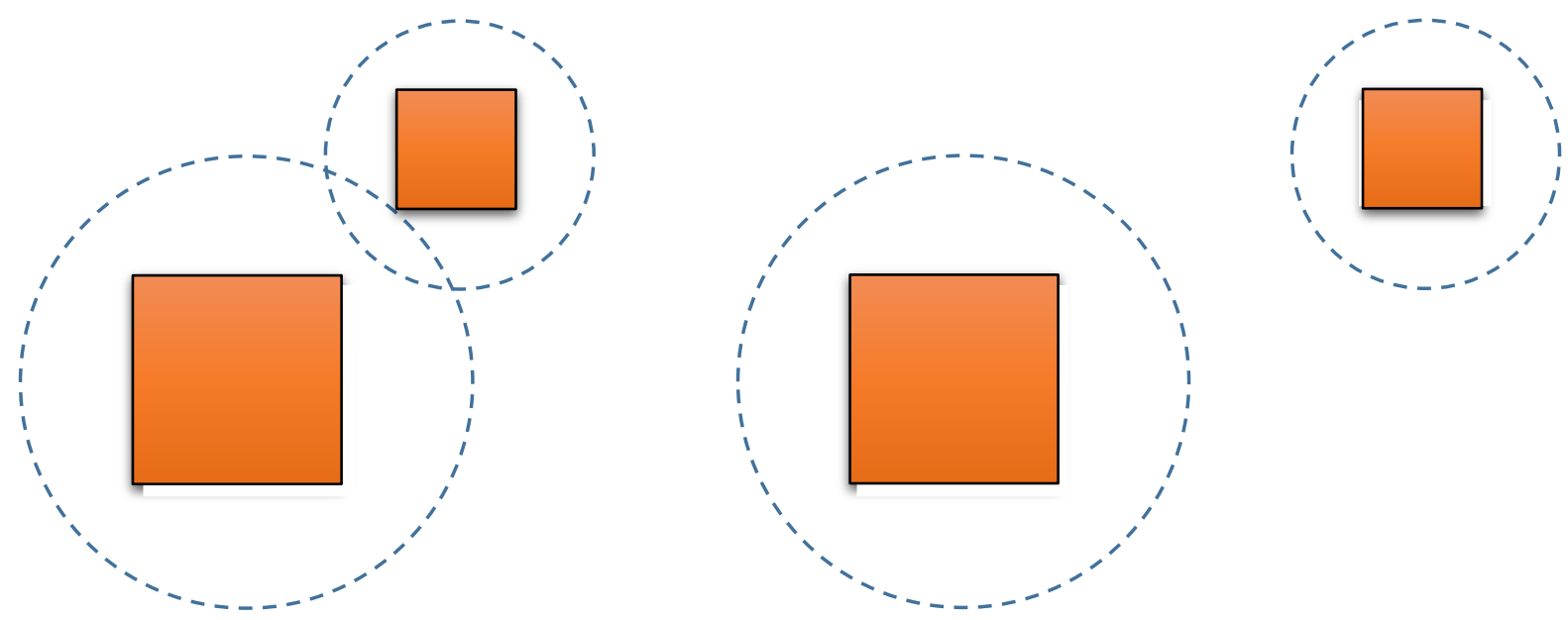

Figure 7. a). Forms are perceived as one composition. b). Forms are separated, and not perceived as one whole. 

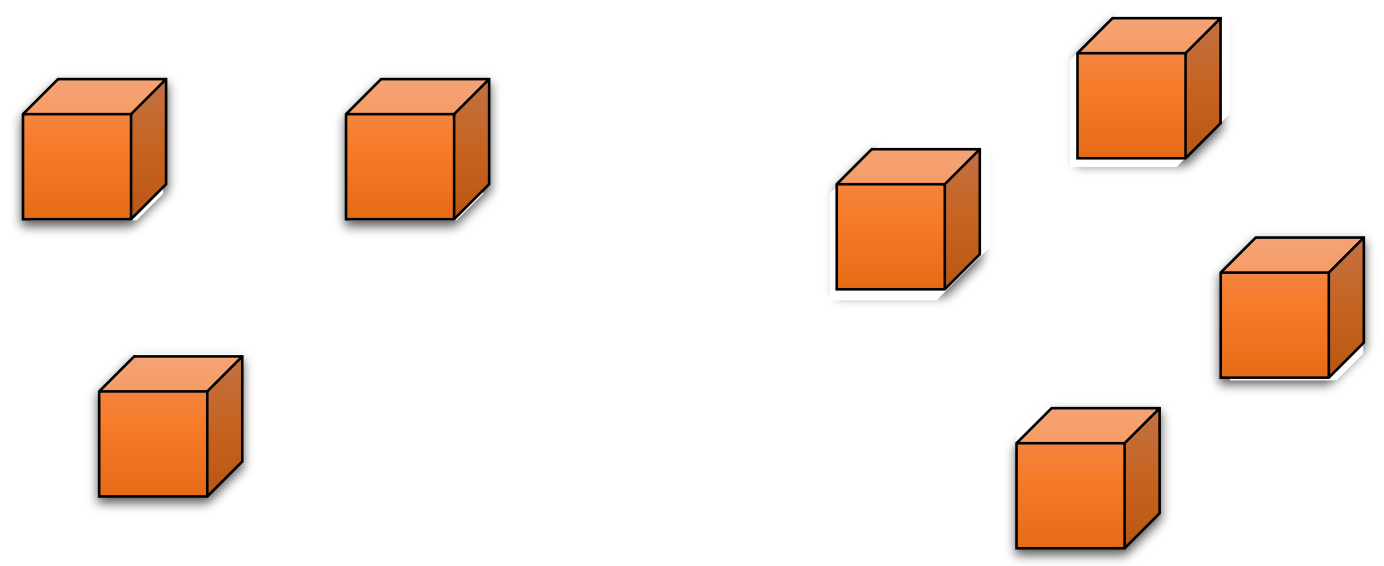

Figure 8. With just a small shifting away from the four elements, the two groups of cubes were formed.

The principle of continuity predicts the preference for continuous figures. We perceive the figure as two crossed lines instead of four lines meeting at the centre as presented in figure below [4].
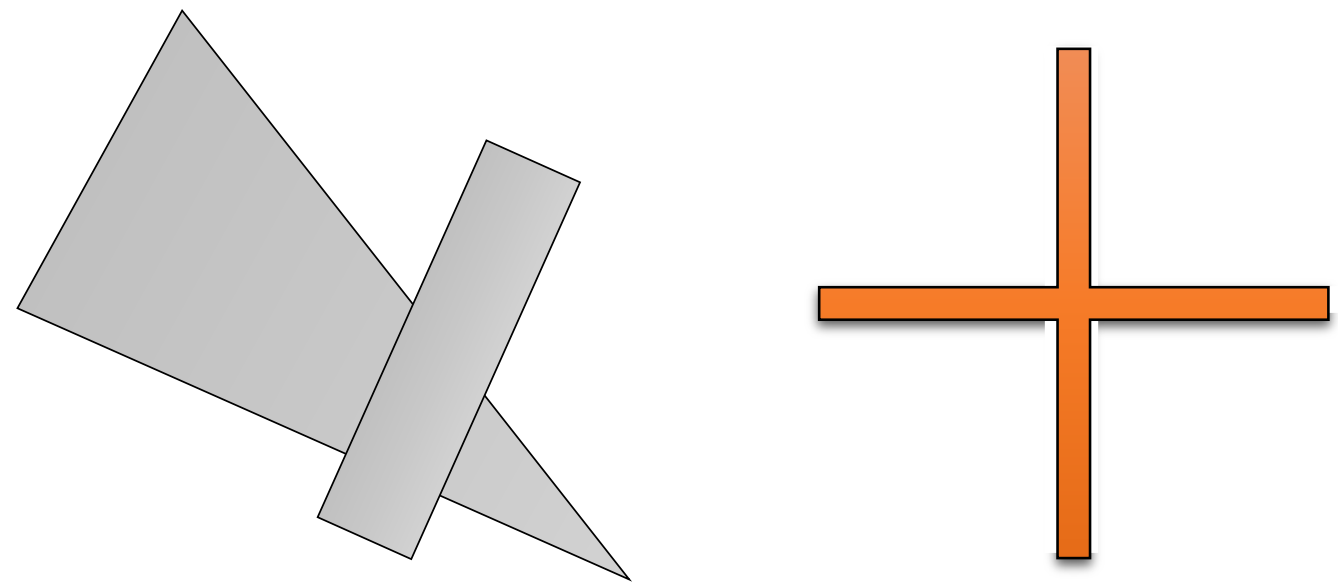

\section{DISCUSSION}

The eye works more or less like a camera. The cornea acts like a glass lens and is the equivalent of the camera's outer lens. The pupil corresponds to the diaphragm and the lens of the eye corresponds to the inside lenses of the camera. The retina is comparable to the film located inside the camera. People spend most of the day at home with a lighting ranging from 50 to 500 lux. Light determines the pace of the biological clock and may have an effect on the circadian system. As stated in many cases and from may authors light is life, good lighting is important to see the world around us, what we want to see needs to be illuminated. Good lighting also affects the way we feel, it also helps in the style and quality of life. 


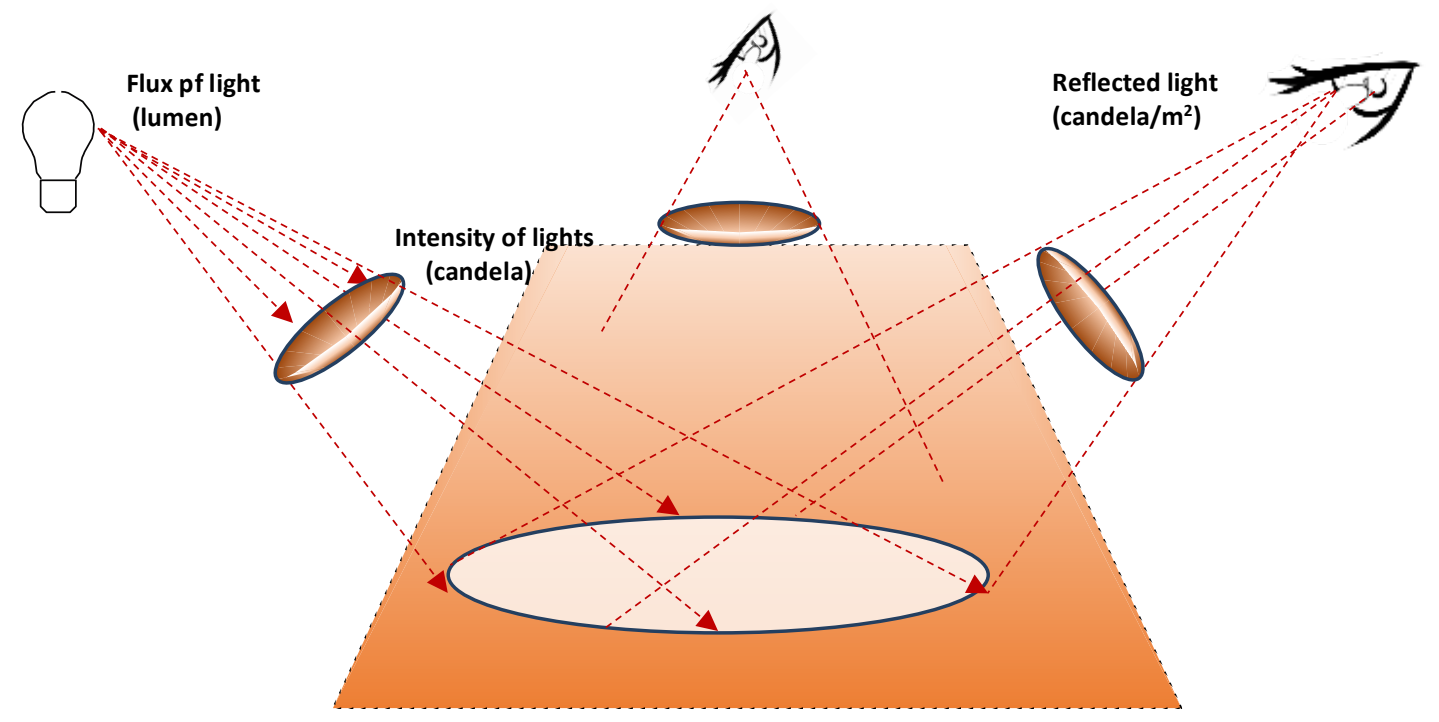

Figure 9. Fundamental meanings, flux and intensity of light, reflected light.

\section{Industrial Functional Compositions}

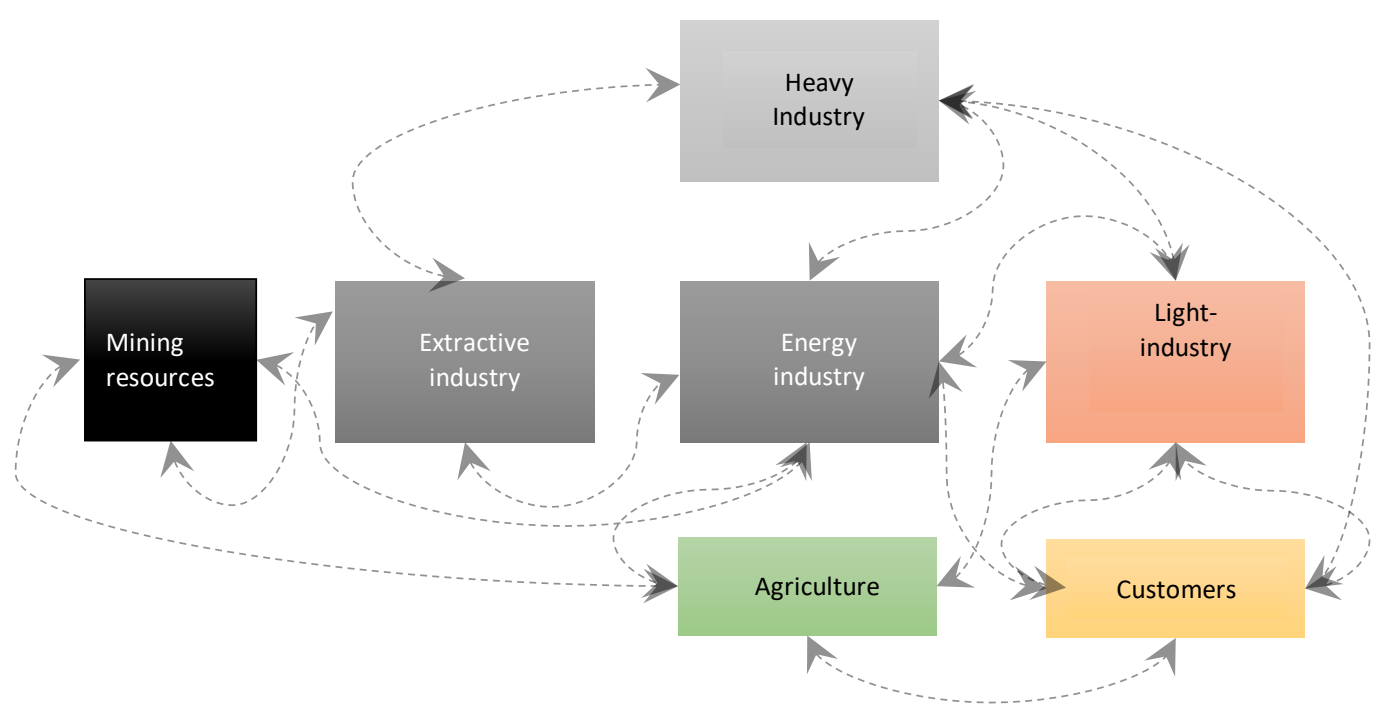

Figure 10. Division of industry's core activities [5].

Actually, this division with regard to activity is quite rough, sometimes not sufficiently clear, so the specific industrial activity is even broader. To illustrate, we can mention the metallurgical industry or the chemical industry which, from their technological process, produce finished processed products, which are intended directly for consumers, but as the industry is not classified in the light processing industry. 


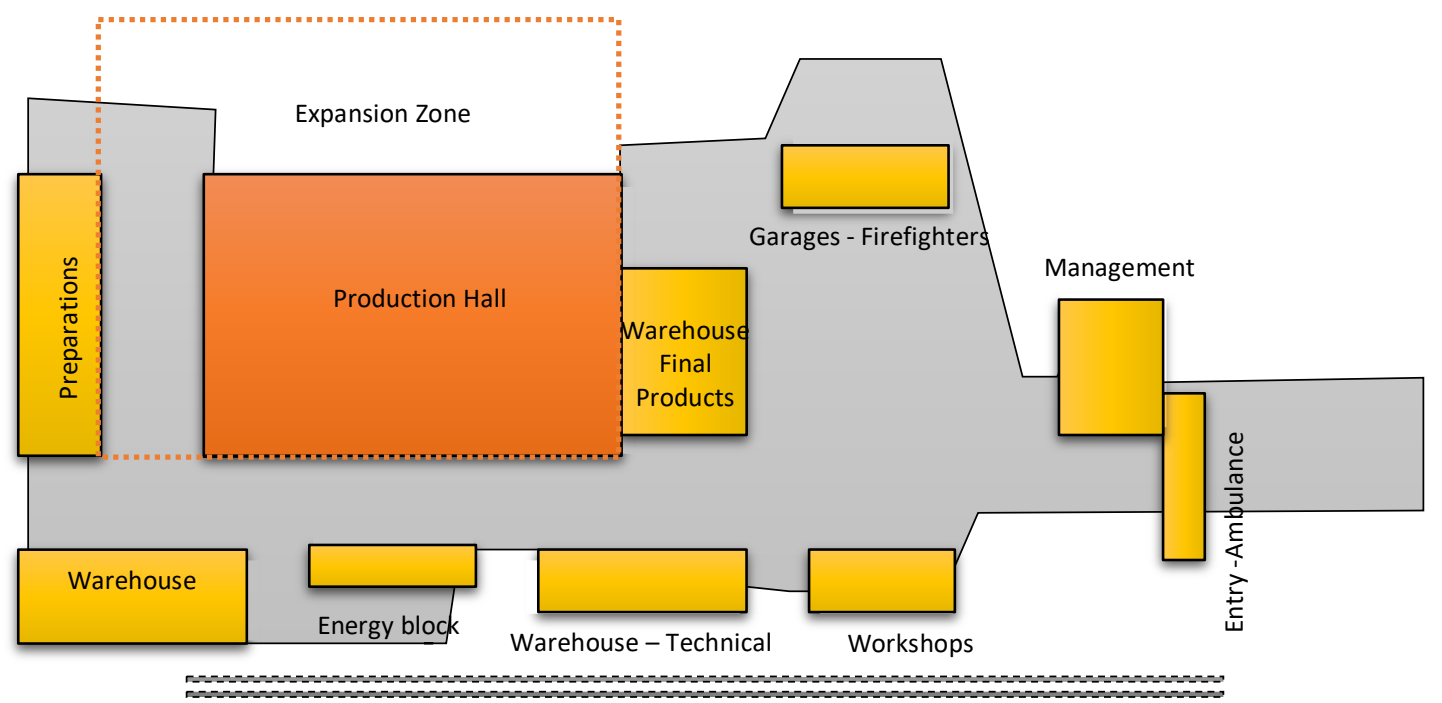

Figure 11. Spatial compositions of the organization of industrial complexes [5].

The functional composition of the organization of industrial complexes is accomplished by attaining successfully functional areas and buildings within the general complex, by fully functionally grouping similar technological processes or adjacent units with common technological features by which are specifically linked [5].

There are several functionally systems of industrial complexes, in terms of architectural modelling concepts and spatial design, these structural compositions can be:

1. Composition with pavilions;

2. Block composition;

3. Mixed Composition;

4. Atrial compositions;

5. Composition of open systems.

The selection of these structural compositions, which will be chosen, will have a direct influence on these functional features:

1. The line of the technological process;

2. Type of activity of the industrial complex;

3. Production capacity;

4. The similarity or diversity of individual areas; 
5. Environmental pollution level;

6. Type of internal transport;

7. Static-dynamic impacts from the manufacturing vehicle tract;

8. Climate influence in the region;

9. Profitability and financial ability of investors [5].

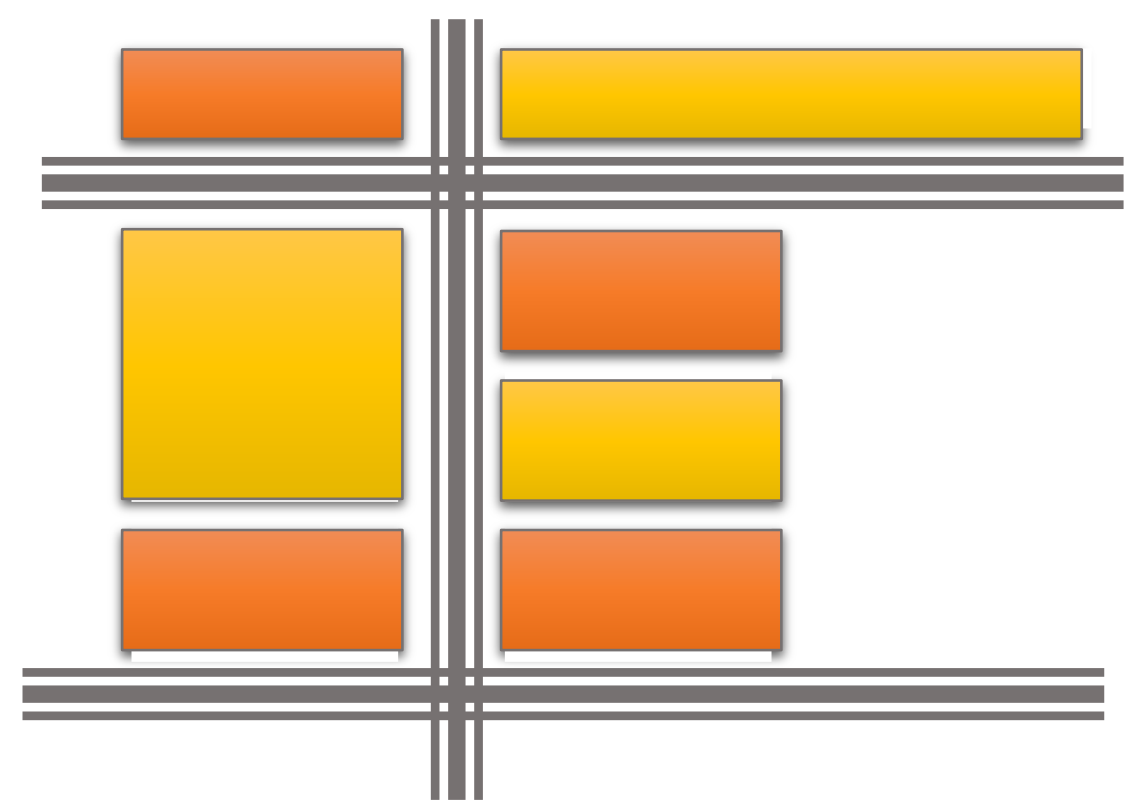

Figure 12. Spatial Composition with grouped forms, Pavilion [5].
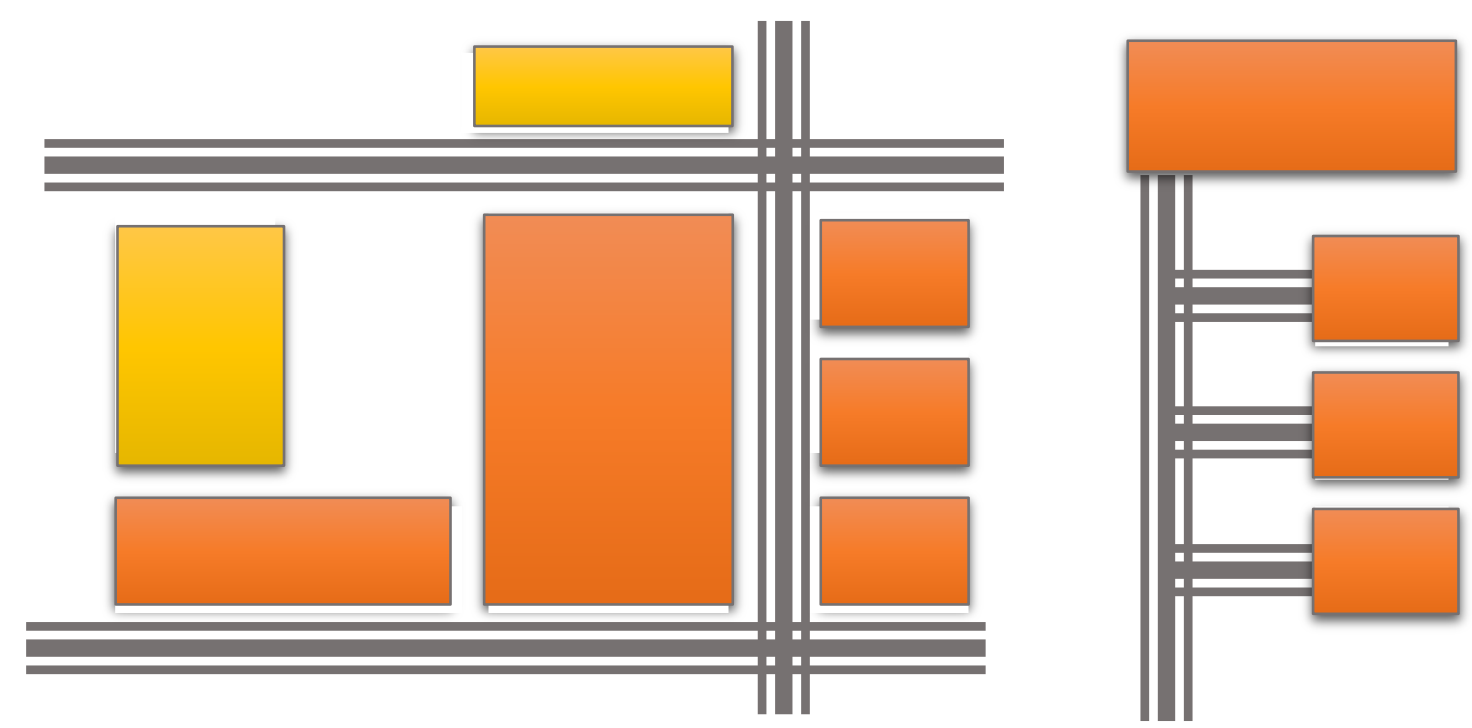

Figure 13. Spatial Composition with grouped forms, Pavilions [5]. 


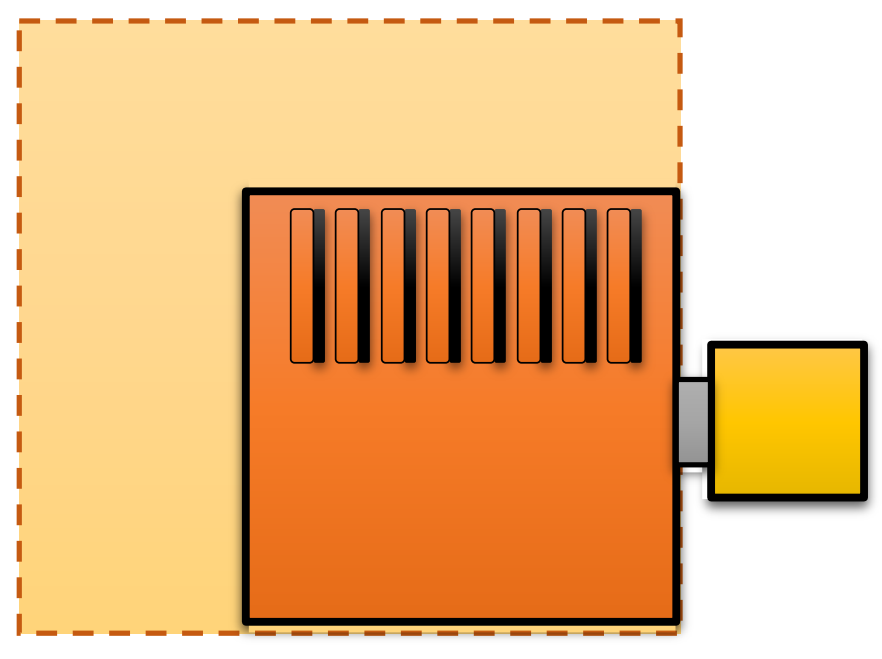

Figure 14. Spatial Composition with Block System [5].
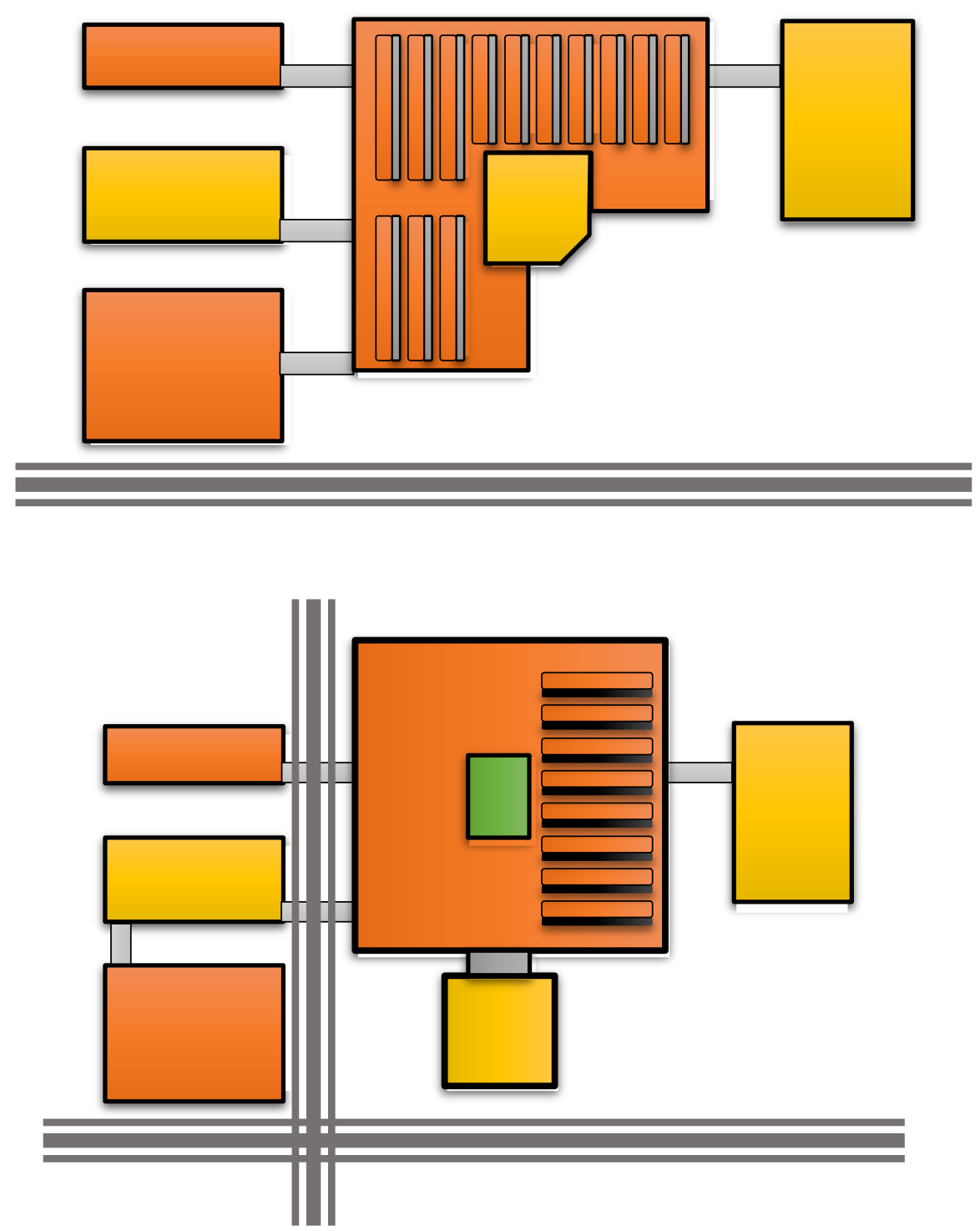

Figure 15. Spatial mixed Compositions, pavilion and block systems [5]. 


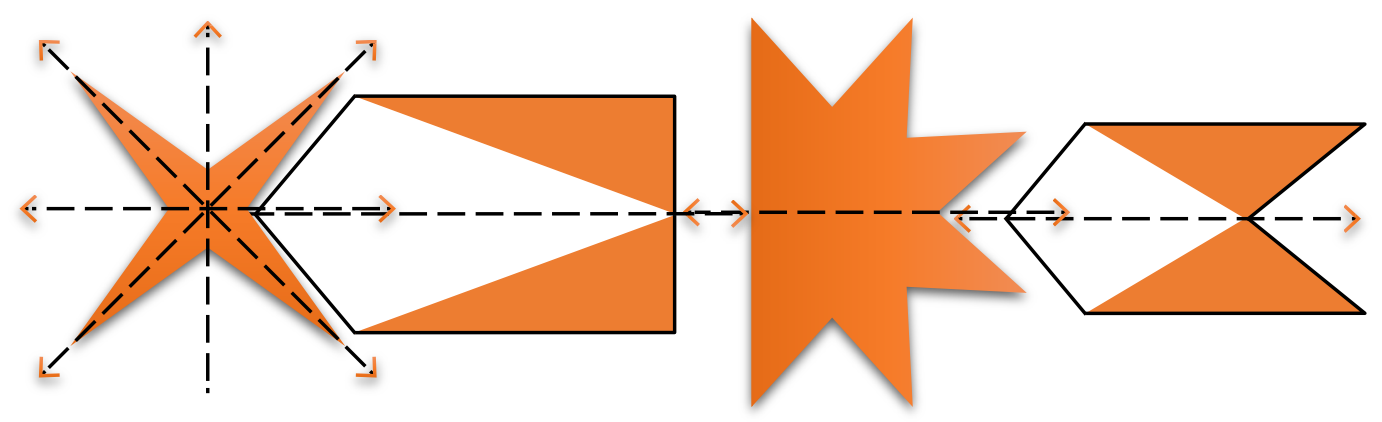

Figure 16. Visual organization of industrial functions [5].

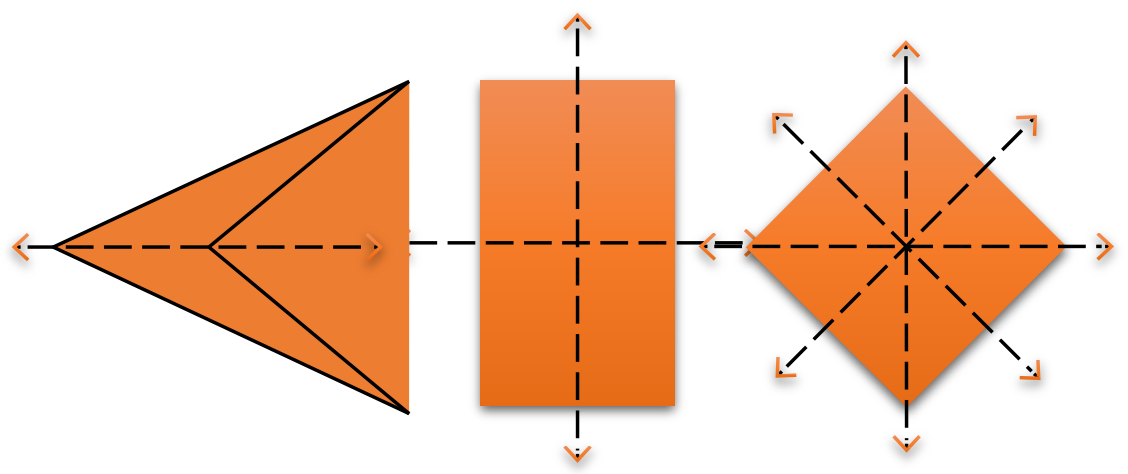

Figure 17. Visual organization of industrial functions [5].

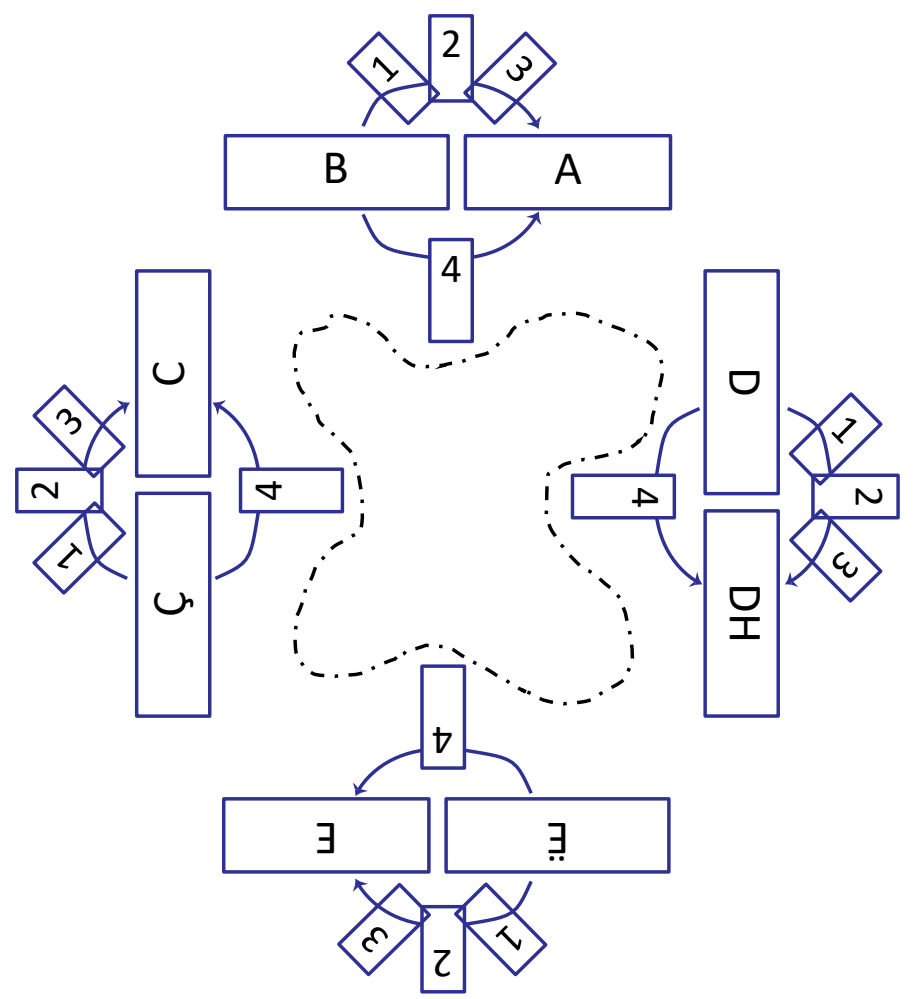

Figure 18. Visual organization of industrial zones in multicomplex compositions [5]. 


\begin{tabular}{l|l|l|l|l|l|l|l} 
& 1 & 2 & & & 1 & 2 & 3 \\
\hline A & & & & & & & \\
\hline & & & & & & & \\
\hline B & & & & & & & \\
\hline C & & & & & & &
\end{tabular}

Figure 19. Visual organization of industrial functions and zones [5].

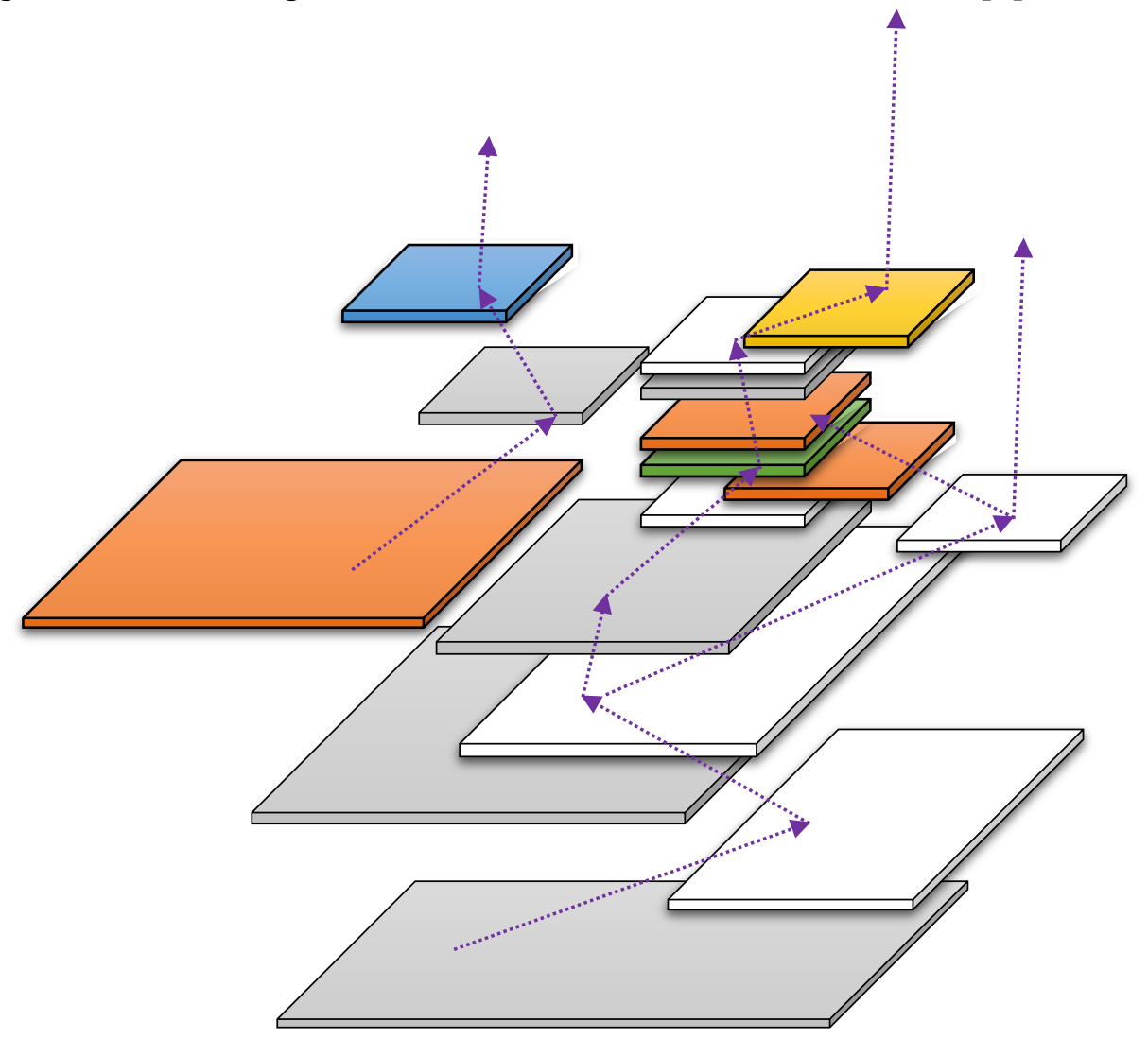

Figure 20. Visual organization of industrial functions, vertical organization [5].
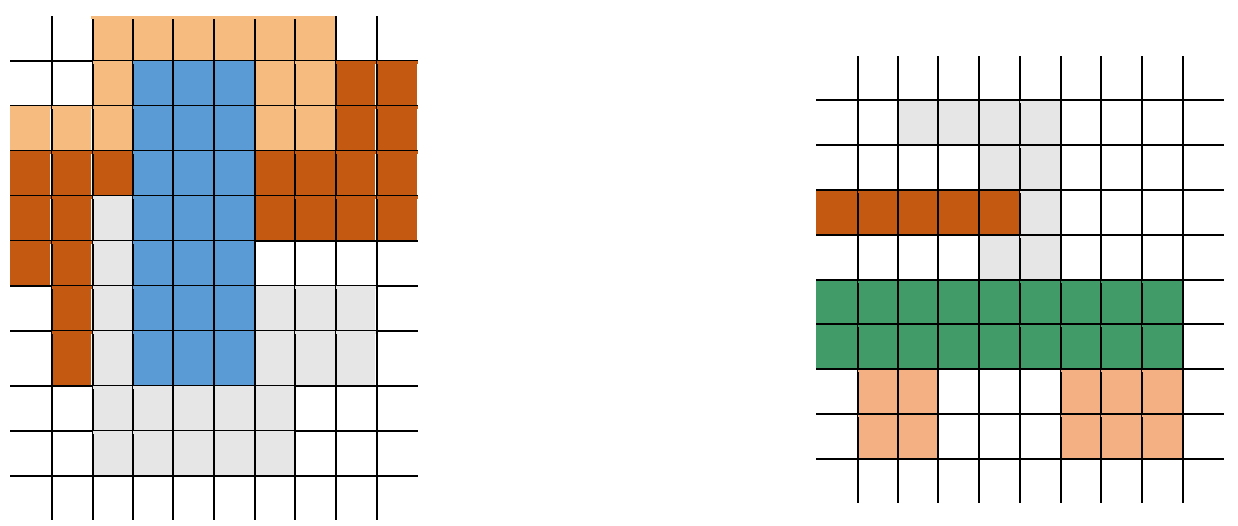

Figure 21. Visual organization of industrial functions in horizontality and zones [5]. 


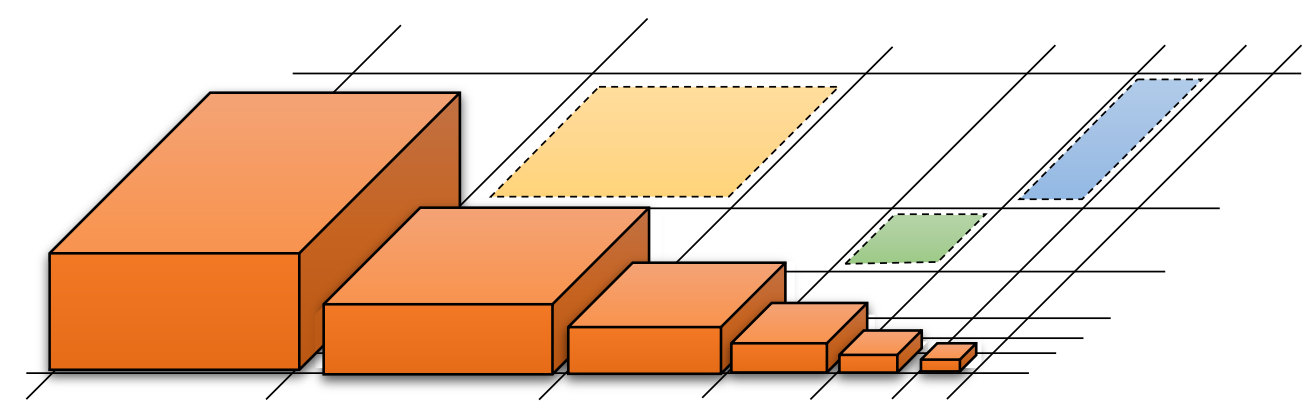

Figure 22. Visual organization of industrial functional volumes [5].
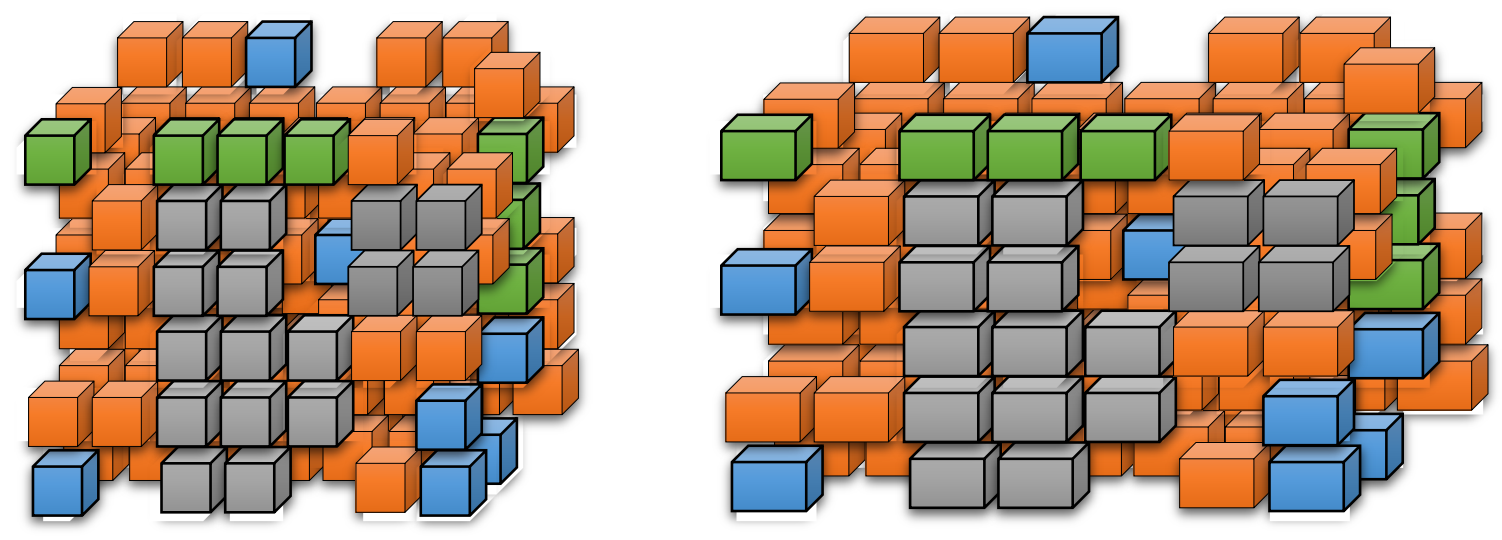

Figure 23. Visual organization of functional volumes [5].

\section{CONCLUSIONS}

Inadequate solving the specific problems of the time, results in mega problems for future generations. The current resolution of the situation, formally fulfilling legal standards cannot solve the present and future challenges. Challenges, associated with the globalisation, development of technology, life style, and global world trends. Specific industrial spatial problems will require specific and original solutions. It is evident that in visual perception we operate by crucial fundamental principles that make us to group visual system components in some meaningful recognizable forms. These logical criterions are of great importance in visual aesthetics and architectural compositions, moreover, this visual grouping is indicative in the wide perceptual range, from the organization of simplest brick wall to the urban composition of metropolitan areas. Thus, design subjectivity and response to context, are also of great importance in architectural design expressions when we are considering the best possible solutions. "The purpose of composition is to express particular concepts and experiences, and it is successful only when these are fully communicated to the observer" [6]. 


\section{REFERENCES:}

[1]. Bajçinovci, B., Jerliu, F. (2016). Complexity of Iterative Model - Architectural Integrated Design as an Evolutive Transdisciplinary Strategy. Case Study: A City Without a River. Journal of Science, Humanities and Arts. JOSHA. ISSN: 2364-0626. Vol. (4), Is. 1. 2017. DOI: 10.17160/josha.4.1.

[2]. Vitruvius, (1914). The Ten Books of Architecture. Translated by Morris Hicky Morgan. Harvard University Press. London, UK.

[3]. Gestalt Principles. (2018). https://etad.usask.ca/skaalid/theory/gestalt/similar.htm\#1 (Accessed: 17 June, 2018).

[4]. Mullet, K. \& Sano, D. (1995). Designing visual interfaces: Communication oriented techniques. Englewood Cliffs, NJ: Prentice Hall.

[5]. Bajçinovci, B. (2017). Sustainable Architectural Design - Principles - in the Albanian Language. JOSHA, Journal of Science, Humanities and Arts. Volume: 4 Issue: 3, Freiburg Germany. DOI: 10.17160/josha.4.3.306

[6]. Encyclopædia Britannica. (2018). Architecture. (Accessed: 10 June, 2018). https://www.britannica.com/topic/architecture/Space-and-mass 